\title{
Use of multi-temporal Earth remote sensing data for the assessment of agricultural area
}

\author{
Anton A. Melentiev* \\ Belgorod State Agricultural University, 1 Vavilova str., Maysky, Belgorod region, Russia, 308503
}

\begin{abstract}
The article discusses the procedure for identifying unused agricultural soils for their use in economic circulation. The object of the research is the Belgorod district of the Belgorod Region, Russian Federation. Methods of planned soil inventory form the basis for identifying unused agricultural soil, the main purpose of which is to assess the reasons for land retirement from active economic circulation, cultural and technical state of landholdings and to prepare recommendations for commissioning soils into agricultural circulation. Agriculture is a vast and vital branch of the national economy of the Russian Federation It is necessary to introduce modern technologies, state-of-the-art machinery, investments as well as to put into action several land management measures in order to facilitate the development of this sector of the national economy. The data provided by Earth remote sensing gives the necessary and relevant information to the customers regarding structure, state and detailed characteristics of agricultural soils and other assets of agricultural production; the line-up, state and growth of crops. Earth remote sensing data allows to solve more complex analytical tasks, such as forecasting crop yield and calculating the optimal doses of fertilizers. It is convenient to use Earth remote sensing data for monitoring and analyzing soils. With the assistance of that data, based on satellite images, it is possible to identify not only the types of crops, but also the degree of weediness, state of yield, accurate field boundaries, sown area and so on and so forth. The aim of this project is to perform automated decryption in ScanEx Web Geomixer software.
\end{abstract}

\section{Introduction}

In the decree of the President of the Russian Federation, dated December 1st, 2012 No. 642 "On the Strategy for the Scientific and Technological Development of the Russian Federation" the concept of "scientific and technological development" is given, and, most importantly, the "big challenges" are listed in which we must formulate our policy. First of all, these are food security and food sovereignty of Russia. Presidential decree dated July 21st, 2016 No. 350 "On measures for the implementation of state scientific and technological policy supporting agricultural development" right now serves as a guidance for the development of agro-industry. In the decree of the President of Russian Federation, dated May 7th, 2018 No. 204 "On state goals and strategic tasks for the development of the

\footnotetext{
*Corresponding author : melentev_07@mail.ru
} 
Russian Federation for the period up to 2024" by the means of introducing digital technologies and multi-platform solutions, the task of conversion of priority branches of economic and social activity, including agriculture is set.

Undoubtedly, domestic producers of agricultural products and foodstuffs, due to a long period of lack of conditions to attract investments and low provision of modern information technologies and technical equipment, lag behind major producing countries with advanced agro-industry in such significant indicators as labor productivity, production cost per worker, yield from 1 hectare, etc. Digital technologies are the key to a breakthrough in this branch.

At this given moment, there are several factors, which impede the implementation of digital tech in Russian agriculture, namely:

1. Sectoral market's huge shortage of experts capable of working efficiently with innovative technologies;

2. lack of incentive to produce goods with guaranteed consumer appeal in the absence of national and international (EAEU) information systems that provide digital traceability of goods;

3. high price of imported designs, dependence on exchange rate fluctuations of world currencies and decisions of world leaders on the adoption of sanctions or other trade restrictions in the context of underdevelopment of the domestic market for digital technologies and solutions;

4. inadequate quality of the documents, which regulate long-term forecasting and planning of the use of land resources in the country as a whole and land resources for agricultural production;

5. incompleteness of data on cadastral registration of all land plots used in agricultural production;

6. lack of national information systems and digital platforms that support agricultural producers with a set of cartographic material of the required scale [1].

\section{Materials and techniques}

According to the materials given in the Decree of the Government of the Russian Federation date December 13th, 2017 No. 1544 "State program for the development of agriculture and regulation of markets for agricultural products, raw materials and food for 2013-2020", one of the points of this complex project is to ensure the preservation and reproduction of soil fertility.

The development of remote monitoring is proposed as a way to solve this problem in the "Concept of state monitoring of agricultural land until 2020". In this Concept the data of remote sensing is considered as the most operational and impartial (independent) information source concerning the fertility of the agricultural soils.

Currently, in the majority of Russian state entities, soil fertility continues to deteriorate, and the state of land used or provided for agriculture is degrading. The ground vegetation, especially that of agricultural landholdings is a subject to degradation and pollution. It loses its sustainability and the capacity to restore potential and reproduce fertility.

Carrying out research on disrupted agricultural soils using remote sensing techniques is especially relevant in regions of intensive cultivation, as it allows to determine the most effective measures for the remediation of soil fertility of lands during land management on an adaptive landscape basis, as well as establishing their value as the main means of production. In this regard, it is necessary to formulate theoretical and teaching guidelines for researching ground vegetation using satellite images. [2].

The processing of remote sensing date is a complex process that includes many operations for various purposes. These operations can relate directly to thematic decryption 
and be auxiliary or compulsory. Remote sensing data techniques are divided into two groups: ones that provide bright and geometric transformations of images, their purpose is to facilitate visual interpretation, increasing its integrity and credibility, as well as to prepare images for subsequent automated decryption and other automated codebreaking methods [3].

Techniques of enhancing transformations are usually utilized as the first step in using images: to identify the pictured areas or objects, to determine their location and to extract data about their visual properties and features, Brightness transformations of images include: radiometric and geometric adjustment of digital images (the elimination of dark pixels, the conversion of brightness to reflectivity, modelling the influence of atmosphere, etc.), improving digital images (changing the brightness and contrast of an image, highlighting contours of a given contrast, filtering brightness values and the highlighting contours in order to select image elements, color synthesis, color-coding), algorithms for transforming images (the method of bilinear and cubic interpolation, creating mosaics of images, etc.) [4].

As noted previously, in recent years, information products and services that have already been created and developed within the framework of specialized monitoring systems that provide collection, processing, archiving and provision of remote sensing data and their processing results on Russian agricultural soils began to be used actively in agrolandscape analysis. Them being the supervision and monitoring within one irrigated agriculture or individual field.

The techniques of decoding based on the transformation of spectral brightness are the main task when using images for researching the soil fertility of agricultural landholdings. Decoding features of objects in images include: tone, color, size, shape, texture, pattern, shadow, location, and connection with other objects. Techniques for synthesizing and analyzing the main components are aims at integrating the features of soil fertility in the spectral space: the first one makes the transition from a three-dimensional representation to a one-dimensional with a new coordinate - color, the second - converts the spectral coordinates into contrast indicators.

To performs the synthesis procedure, three zonary images are selected, which are considered as the red, green and blue elements of RGB palette ( $\mathrm{R}$ - "red" with a wavelength of 0.7 micrometers; G - "green" with a wavelength of 0.5461 micrometers; B - "blue" with a wavelength of 0.4358 micrometers) [5].

During the landscape analysis, the transformation of the main elements is used to obtain integral characteristics of the landscape based on heterogeneous data - satellite images, digital terrain models, ground data, cartographic materials. The main elements act as such integral characteristics. During the automated decoding full (supervised classification) or partial (non-supervised classification) elimination of human effect on result obtained is possible. Situation such as this usually happens during the remote research of soil diversity, and utilization of non-supervised classification lowers the subjectivity of demarcating boundaries. The classification process consists in the allocation of all image pixels into classes in accordance with the reflectivity (spectral brightness value) of each in one or more areas of the spectrum.

\section{Research Questions}

According to the Ministry of Agriculture of the Russian Federation, underutilized agricultural soil is 52.2 mil. hectares, however, based on the statistics of the Kommersant newspaper, No. 3 (6724) dated January 11th, 2020, soil retired from active economic circulation is about 44 million hectares and 20 hectares of them are arable land. For 
comparison, these soils cover an area larger than the combined area of $75 \%$ of European countries.

An analytical review of statistics on the identifying the underutilized agricultural landholdings indicates the ambiguity and the presence of methodological gaps.

On the one hand, even such a large figure within our country is, again, according to the Ministry of Agriculture of Russian, only 13.6\% of all agricultural landholdings.

On the other hand, for starters, the situation is complicated by the uneven retirement of agricultural landholdings in the regions. Secondly, this figure does not seem to be final, since when analyzing data provided by other organizations, for example, Rosreestr, the percentage of underutilized land in a number of regions is much higher than according to the data of the Ministry of Agriculture of Russia [6].

To carry out automated decoding of agricultural soils, a work site was selected, located on the territory of the Belgorod district of the Belgorod region, ( Fig. 1. ).

According to the results of the All-Russian Agricultural Census of 2016, which was carried out by the territorial body of the Federal State Statistics Service for the Belgorod Region (Belgorodstat), the territory of the Belgorod District is 88381.0 hectares, of which 83107.7 hectares, including 72,543.6 arable land, 1465.6 hayfields, 6715.6 hectares of pasture, 1353.4 hectares of perennial plantations and 1029.7 hectares of deposits.

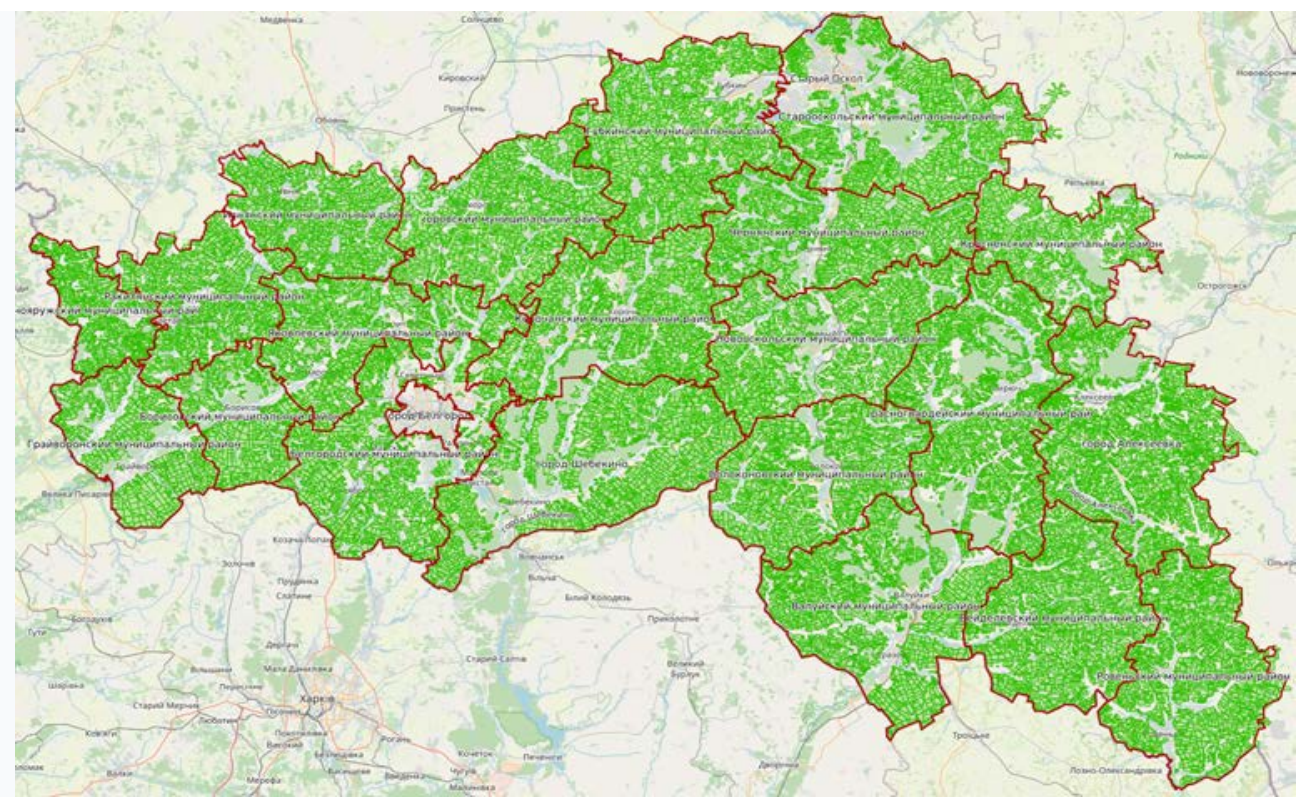

Fig. 1. Vector layer of the Belgorod region fields.

Using combinations of spectral channels of Landsat data, it is possible to color images in original and false colors, which helps to identify decoding features in the image. Many features can be identified by applying different combinations of Landsat data channels for agricultural areas.

The combination of spectral channels 3-2-1 of Landsat 7 data (or 4-3-2 for Landsat 8) in original color displays terrain as it is in reality. In this image, the vegetation look green, the harvested field are yellow, the roads are gray and the coastlines are whitish.

A combination of spectral channels 4-3-2 for Landsat 7 (or 5-4-3 for Landsat 8) "artificial colors" is used to research the state of vegetation, to monitor drainage and soil mosaic, and to study crops behavior. The image in this data combination displays vegetation in shades of red, urban areas in green-blue, and soil colors ranging from dark to 
light brown. Ice, snow and clouds appear white. Coniferous forests look deep red or brown. This combination allows to determine the degree of plants growth. For agricultural soil, growth allows to separate the types of agricultural soils and types of crops.

Index images are another automated decryption technique. The brightness values of each pixel of such an image is determined by applying arithmetic operations on the brightness values of this pixel from different image channels. For agricultural purposes, such indices as NDVI, MCARI, MATVI2, etc. are used, calculated in the ScanEx Web Geomixer software package for automated decryption.

The NDVI index image is a simple quantitative indicator of the amount of photosynthetically active biomass (commonly referred to as the vegetation index). One of the most common and used indices for solving tasks using quantitative estimates of vegetation cover.

Vegetation index (NDVI) - characterizes the state of the vegetation cover (varies from 1 to 1 ), the higher the vegetation index, the better the state of agricultural crops. For green vegetation, the reflection in the red zone of the spectrum is always less then in the near infrared, due to absorption of lights by chlorophyll, so the NDVI values for vegetation cannot be less then 0 .

NDVI also characterizes the density of vegetation, allows plant breeders to assess the germinative capacity and growth of plants, the productivity of soil. The calculation of the index for each pixel of the satellite images in the red and near infra-red spectral zones allows you to receive a derived image - the NDVI map.

NDVI allows you to identify problem areas of oppressed vegetation, making it possible to make the most correct long-term decisions aimed at increasing yields. Areas with different vegetation conditions or the amount of green phytomass can be depicted in different colors. With the help of statistical processing of NDVI maps, in addition to determining the amount of phytomass, it is also possible to distinguish the areas under crops of various crop plants.

Using the vegetation NDVI index in the ScanEx Web Geomixer software, it was possible to divide the types of crops according to the value of the brightness of pixels per image. Zones with bright pixels showed a high chlorophyll content in the plants, which also signified a high degree of vegetation. The murkier zones indicated the absence of vegetation (Fig. 2.).

From the materials of the automated decoding of agricultural soils, it is evident that fields occupied by spring crops are displayed in dark brown, winter crops in yellow and green, and field that are not involved in agricultural circulation are shown in blue. 


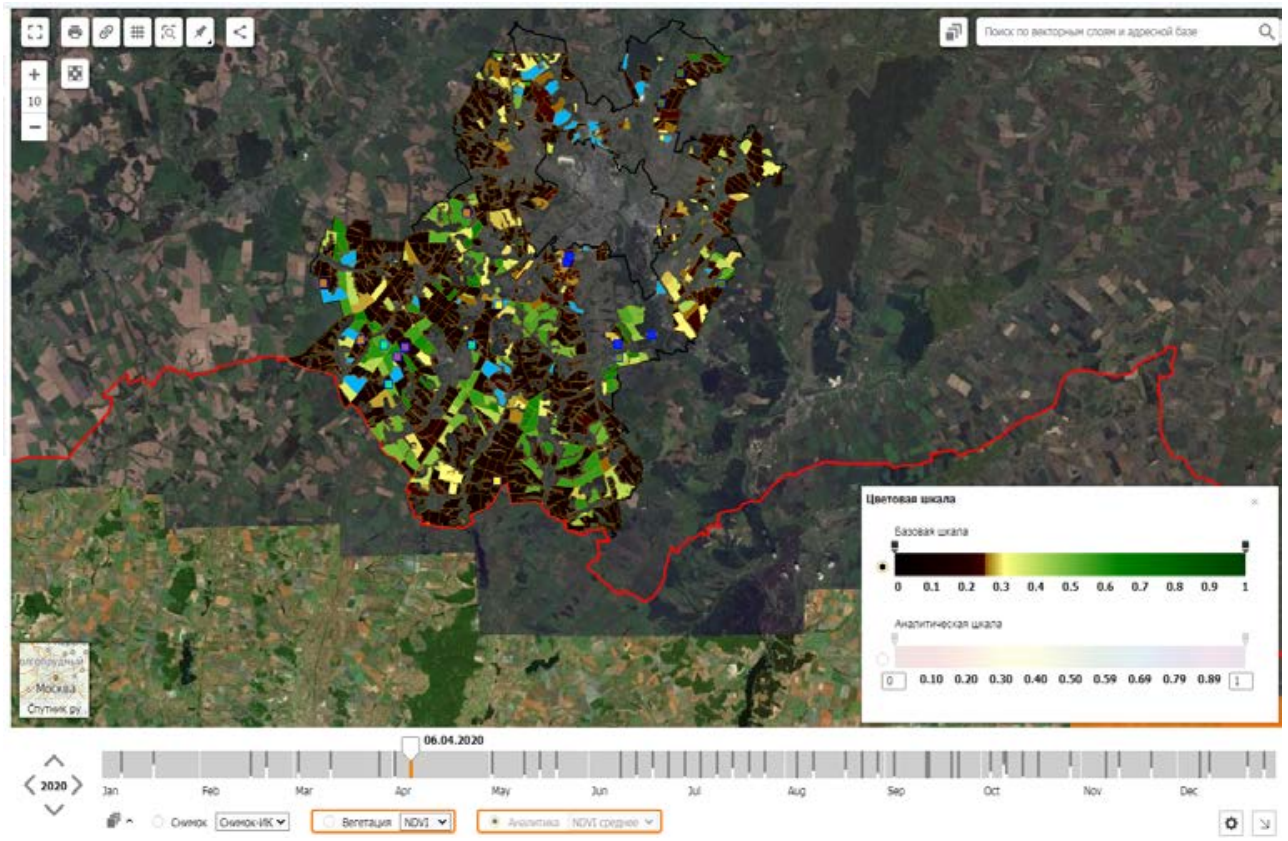

Fig. 2. NDVI data analysis is the average for the territory of Belgorod region.

\section{Conclusion}

Observing the ongoing changes in agricultural landholdings, it is possible to perform monitoring of agricultural territories, which would allow to predict the development of agricultural sector and apply solutions to agricultural problems in this territory.

In October, the first shoots of winter grain crops appear on the sown areas. After the winter precipitations, the crops do not die, but continue to grown after the snow melts. From October to March, the research of the dynamics of the snow cover in cultivated areas is carried out. An assessment of moisture accumulation, flood situation, readiness of landholdings for the next season is also carried out.

In April, after the snow melts, winter crops, freed from the snow, continue to grow, which are shown in original colors in green tones on the satellite image. At the beginning of May, preparations for sowing grain crops are already beginning, peeling and cultivation are done, and by the end they begin to sow grain crops into the soil.

In April and May, remote sensing data allows:

1. to determine the area of arable land occupied by winter crops.

2. to determine the area of land without autumn post-harvest tillage.

3. to assess the state of winter crops for identifying and measuring the area of degraded and dying winter crops ranges.

4. to determine the area of land on which engineering and reclamation measures have been carried out.

5. to determine the area of land occupied by agricultural crops.

In June, the first shoots of spring grain crops appear on agricultural fields, plowing, fallow processing, and winter crops harvesting are conducted. In July, perennial and annual crops bloom. Also in July, winter crops are harvested and hay-mowed.

High Resolution satellite images allow to solve the problems of researching the hydrological mode of soils, establishing the sources and boundaries of irrigating, identifying (by indirect signs) the areas of distribution of various plant species. Remote 
sensing data helps to monitor the state of natural lands, pastures and hayfields; to identify and control the development of erosion processes and develop anti-erosion measures.

Thus, the initiated active introduction of techniques for solving tasks using remote sensing data raises agricultural production to a whole new level.

\section{References}

1. I.M. Donnik, Digital agriculture - basis for sustainable socio-economic development of the Russian Federation. Land management education and science: from the 18th to the 21st century. Materials of the International Scientific and Practical Forum dedicated to the 240th anniversary of the State University for Land Management in 2 V. Ed. by S.N. Volkov, D.A. Shapovalov. - Vol. 1. GUZ. - M., (2019). - 400 p. - pp. 8 - 14.

2. S.M. Vasiliev. Yu.E. Domashenko. L.A. Mityaeva, M.A. Lashkov, A.O. Matvienko, Yu. Glushchenko. Review of the main methods for assessing disturbed agricultural lands using remote sensing data of the Federal State Budgetary Scientific Institution 'Russian Research Institute for Melioration Problems', Novocherkassk, (2018).

3. I.K. Lurie. Theory and practice of digital image processing. Remote sensing and geographic information systems: textbook. Manual for universities. M.: Scientific world Publ., 2003. - 168 p.

4. Yu.F. Knizhnikov. Fundamentals of aerospace methods in geographical research. - M.: Moscow State University, 1980. - 137 p.

5. M.Yu. Zhilenev. Review of the application of multispectral remote sensing data and their combination in digital processing. Geomatics. - 2009 - No. 3. - pp. 56-65.

6. E.V. Cherkashina, O.A. Sorokina, I.V. Fomkin, A.V. Fedorinov, L.E. Petrova. Identification of unused agricultural lands and their involvement in economic turnover based on planned land inventory. Land management, cadastre and land monitoring. No. 11, (2020). 